\title{
MATLAB/Simulink Model for Optimization of Tilt Angle of Solar Panels Using Weighted Average Method, VIT University
}

\author{
Shaurabh K. Singh ${ }^{1}$, *Utsav A. Jain ${ }^{1}$, Gundabattini Edison ${ }^{1}$ \\ ${ }^{I}$ School of Mechanical and Building Sciences, VIT University, India
}

\begin{abstract}
The output of a solar panel depends on various factors and one of them is the tilt angle of the panel. Though small changes in the tilt angle might not cause great difference in the output of a panel but when we talk about huge solar photovoltaic plants, even a small difference in solar tilt may result in loss of hundreds of kilowatt. This paper focuses on optimizing the tilt angle for fixed support panels at VIT University (Vellore, India). The paper lays more focus on weighted average calculation of tilt angle rather than calculation of simple average. The graphical and analytical calculations as well as Simulink analysis gives an accurate tilt angle of $19.5640^{\circ}$ instead of $17.7093^{\circ}$ which is found by simple averaging method in MATLAB. Though this 2 degrees difference would not matter for small plants but for plants with more than $5 \mathrm{MW}$ capacity, this optimization of 2 degrees can help save a lot of energy.
\end{abstract}

Keywords: weighted average, zenith angle, declination angle, MATLAB Simulink, optimum solar tilt angle, solar azimuth angle.

\section{Introduction}

The importance of renewable form of energy increases with the increase in population as well as the style of living. Among the renewable sources of energy, solar photovoltaic has proved to be promising because of its easy and efficient way of energy production. Sun is a huge source of solar energy and it is time that we utilize it to the maximum level. Though this form of energy is very easy to generate but at the same time its efficiency is very less due to many reasons. One of the confusions or dilemmas that engineers face is the tilt angle of the panels, whether to keep it fixed or to vary it according to the season ${ }^{[1]}$. The advantage with the latter is that if the panel follows the sun, it can collect all the energy and hence give high energy output. But at the same time the equipments used to track the sun are so expensive that even after the increase in efficiency, they are not feasible to be installed in huge solar photovoltaic plants. A lot of research has been done at attempts to make this system feasible ${ }^{[6][11][12]}$.

This paper focuses on an alternate and a cheaper methodology for increasing the output of the panels. This methodology does not require any cost but uses weighted average technique to refine the formula for calculating optimum tilt. It assumes fixed support type of solar panels and takes the radiation data of the past years, assigns weights to each and every month and then calculates the optimum tilt to minimize the losses.

\section{Analytical Calculation For Tilt Angle}

The solar zenith angle is the angle measured from directly overhead to the geometric centre of the sun's disc, as described using a horizontal coordinate system ${ }^{[16][17][18]}$. For maximum efficiency of a solar panel or a PV system, the direct rays of the sun should fall perpendicular to the panels and hence determining the tilt angle of the panel is very important. The tilt angle varies every minute of the day and every day of a year. So for fixed PV System, we have to keep an optimum tilt angle for maximizing the output.

The intensity on a solar module is calculated by using the following formula:

$$
\begin{gathered}
S(\text { Module })=S(\text { Incident }) \times \sin (\alpha+\beta) \\
\alpha=\text { Elevation Angle }=90-\theta_{z}
\end{gathered}
$$

Therefore, for Module power to be equal to incident power;

$$
\begin{gathered}
(\alpha+\beta)=90^{\circ} . \\
\beta=90-\alpha \\
\beta=\theta_{z}
\end{gathered}
$$

So from these analytical calculations we can say that the tilt angle at any particular location should be equal to the solar zenith angle at that moment. But for fixed solar systems, the tilt angle is constant and doesn't vary with time. So we have formulated a methodology that can find a fixed tilt angle that can give maximum averaged solar output annually.

The formula to find the zenith angle can be given as ${ }^{[17][18]}$ : 


$$
\cos \theta_{z}=\sin \Phi \sin \delta+\cos \delta \cos \Phi \cos \omega
$$

$\Phi=$ Latitude $\left(12.973870^{0}\right.$, VIT University)

$\delta=$ Declination Angle

$\omega=$ Hour Angle ${ }^{[4]}=15(12$ - LST)

LST $=$ Local Solar Time

Here, the declination angle is defined as the angle between the line of equator and the line joining the centre of sun and the earth. For equinoxes the angle of declination is zero whereas it is maximum at summer and winter solstice. Taking elliptical orbit of the earth around the sun, the formula used to calculate the angle of declination at a point is given by ${ }^{[2]}$ :

$$
\begin{gathered}
\delta(\text { in radians })=0.006918-0.399912 \cos \Omega+0.070257 \sin \Omega-0.0006758 \cos 2 \Omega+0.000907 \sin 2 \Omega- \\
0.002697 \cos 3 \Omega+0.00148 \sin 3 \Omega
\end{gathered}
$$

$\mathrm{d}=$ day number of the year

$$
\Omega=\frac{360(d-81)}{365}
$$

The solar azimuth angle is the azimuth angle of the sun ${ }^{[5][13]}$. It defines the direction in which the sun is, whereas the solar zenith angle or its complementary angle solar elevation defines how high the sun is. It is given by the formula below ${ }^{[5][14][15]}$ :

$$
\cos \lambda=\frac{\cos \Phi \sin \delta-\sin \Phi \cos \delta \cos \omega}{\cos \left(90-\theta_{z}\right)}
$$

Below is a graph showing the variation of tilt angle or the solar zenith angle with the days of year at solar noon (maximum output is assumed at solar noon). This output is obtained as a result of mathematical simulation using the principle of absolute average in MATLAB.

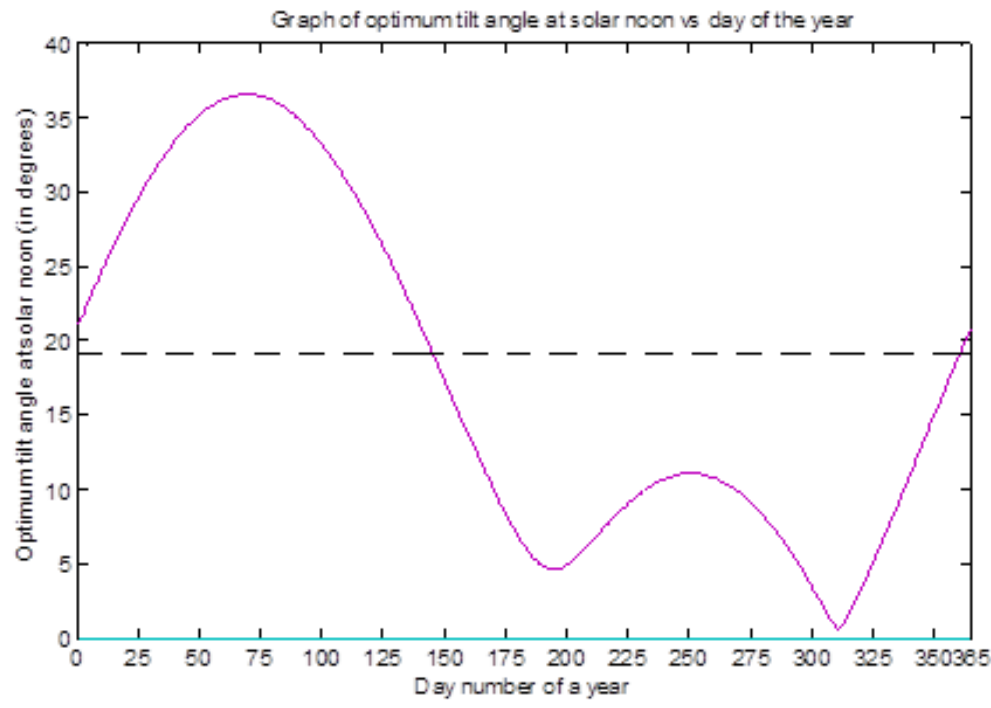

Fig. 1 Variation of Optimum Solar Tilt Angle in a year (VIT University)

\section{Simulink - Development Of Mathematical Model And Design}

The MATLAB software and its graphical application Simulink have the ability to design and simulate static and dynamic systems. For this we have designed a variety of components that form a library for the simulation of Solar tilt angle variation throughout a year in Simulink.

The mathematical equations used in designing the Simulink model are equations 1, 2 and 3. The Simulink model shows the solar tilt angle calculator where LAT and LONG are the latitude and longitude of Vellore respectively and Scope and Scope1 are the final outputs - azimuth angle and the solar zenith angle respectively. This model can be used to find the solar tilt angle for any particular day of the year or collectively a group of days, like a month or a whole year. Further, it can be modified and used to find absolute and weighted average of a definite period of time. 


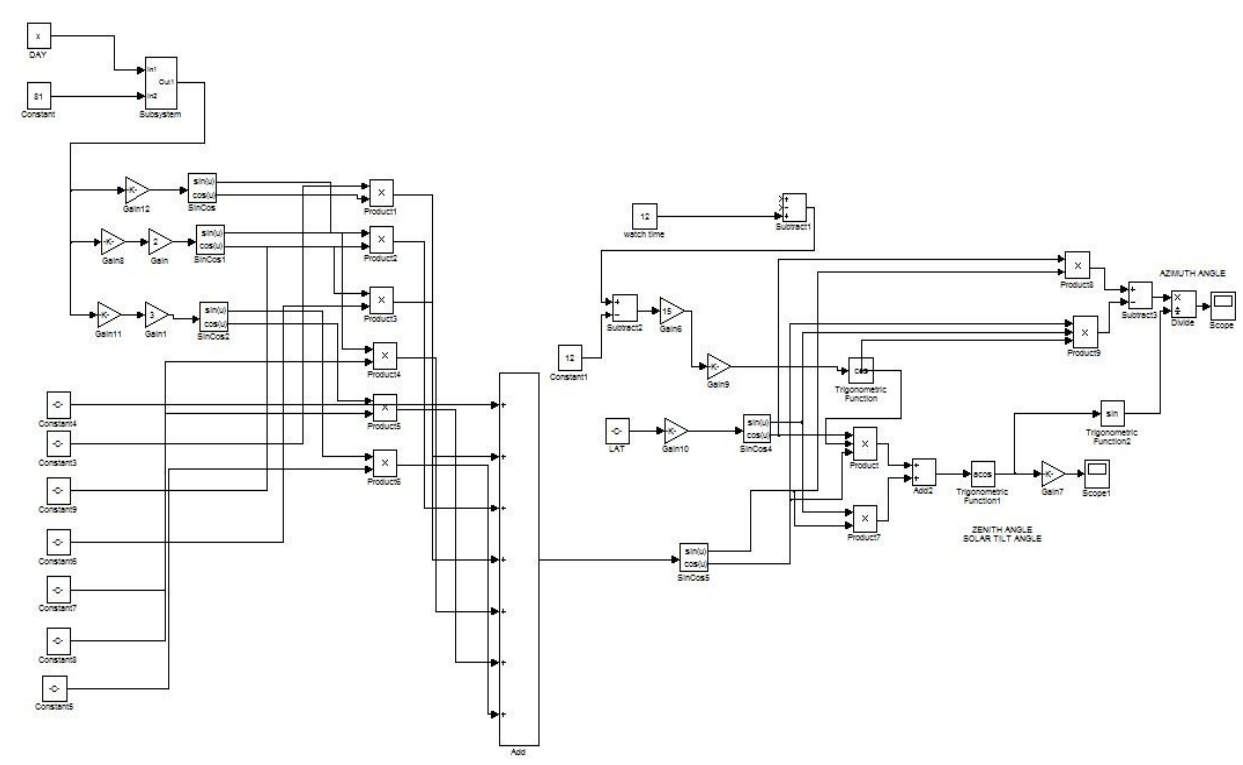

Fig2 Mathematical Model of Calculating Optimum Solar Tilt Angle and Solar Azimuth Angle of places whose latitude and longitude are known (MATLAB Simulink)

\section{Weighted Average Method To Calculate Tilt Angle}

The absolute average method gives an approximate value of tilt angle but not accurate. For example, if solar output is maximum in month of March, we can say that this month should be given more weight while calculating the tilt angle. This makes sure that when solar input is maximum, the tilt angle and the optimal tilt value are as close as possible.

Weighted average can be defined similar to arithmetic mean but instead of giving equal weightage to all the data points, particular weight is given to each depending on the parameter. The weighted average for 12 months can be calculated by using the following formula:

$$
\begin{gathered}
\beta=W_{J a n} \beta_{j a n}+W_{F e b} \beta_{F e b}+W_{M a r} \beta_{M a r}+\ldots \ldots \ldots+W_{D e c} \beta_{D e c} \\
W_{J a n}=\frac{I_{J a n}}{I_{J a n}+I_{F e b}+I_{M a r}+\ldots \ldots . .+I_{D e c}}
\end{gathered}
$$

\section{Figures And Tables}

1. Tabulation and comparison between absolute and weighted average value of optimum tilt angle.

Table 1. A Comparison of the Optimum Tilt Angle found by absolute and weighted averaging (All months in a

\begin{tabular}{|c|c|c|c|c|}
\hline \multirow[b]{2}{*}{ MONTH } & \multicolumn{2}{|c|}{ ABSOLUTE AVERAGE (IN DEGREES) } & \multicolumn{2}{|c|}{ WEIGHTED AVERAGE (IN DEGREES) } \\
\hline & ABSOUUTE MONTHLY AVERAGE OF TILT ANGLE & $\begin{array}{l}\text { MONTHLY CONTRIBUTION TO TILT ANGLE } \\
\text { (CONSIDERING AVERAGE SOLAR INTEUSTTY } \\
\text { THROUGHOUT THE YEAR) }\end{array}$ & $\begin{array}{l}\text { WEGHTED MONTHLY AVERAGE OF TIUT } \\
\text { ANGLE }\end{array}$ & $\begin{array}{l}\text { MONTHLY CONTEIEUTION TO TILT } \\
\text { ANGLF (CONSIDERUNG SOLAR } \\
\text { ENTENSTY BY MONTH) }\end{array}$ \\
\hline IANUAAEY & 26.50930792 & 2.205108993 & 25.85177551 & 209060604 \\
\hline FEBRLAARY & 34.22599255 & 2.852157713 & $34.230 \times 22229$ & 3.1570640075 \\
\hline MARCH & 36.13972335 & 3,011643512 & 35.14539134 & 3.923593004 \\
\hline Aphin & 31.76027043 & 2.545689203 & 31.89587745 & 3.234917804 \\
\hline MaY & 22.5065455 & 1.875553792 & 22.95254311 & 219493926 \\
\hline NUNE & 11.45744564 & 0.554787137 & 12.23650095 & 1027321689 \\
\hline NLY & 5.365542222 & 0,446878519 & 5.457437125 & Q.419417415 \\
\hline AUGUST & 9.241815602 & 0.770151384 & 2.397522599 & 0.709633998 \\
\hline SEPTEMEER & 10.62590411 & 0.885825342 & 1a.65183288 & 0.879061454 \\
\hline OCTOBER & 5.233975966 & 0.515499072 & 5.927470642 & 0.489905793 \\
\hline NOVEMBER & 3.606933793 & 0.305677817 & 5.269976662 & 0.339586674 \\
\hline DECEMBER & 14.81358187 & 1.234455155 & 15.69573277 & 1053839023 \\
\hline & & 17.70933674 & & 19.56402627 \\
\hline
\end{tabular}
year at VIT University) 
2. A graphical comparison showing the significance of weighted over absolute averaging. Fig. 3 depicts the calculation of optimum tilt without taking into consideration the solar irradiation of each month. While Fig. 4 shows the variation in absolute and weighted optimum tilt angle considering the monthly solar irradiation.
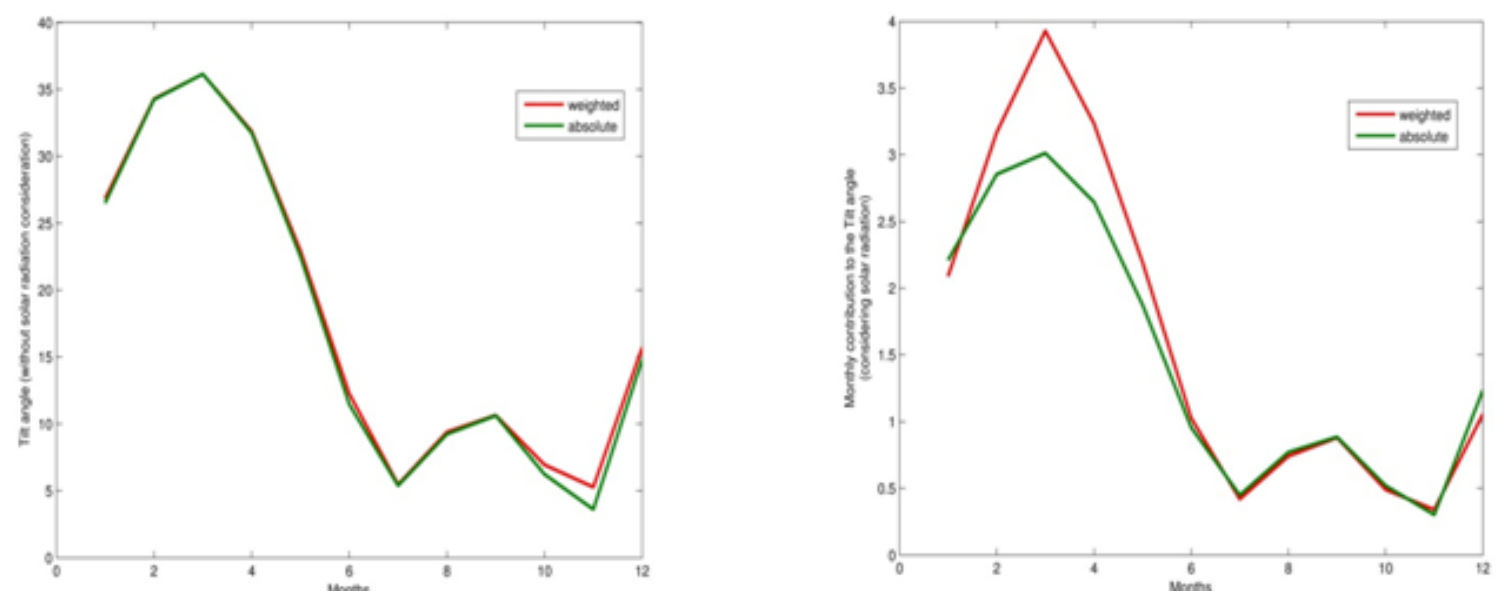

Fig. 3 and 4, Graphical comparison of tilt angle with and without consideration of weights due to solar irradiation in a month.

3. Daily variation of optimum tilt angle for four seasons in a year using Simulink Design (For this research we have taken into consideration, the months of March (Spring), June (Summer), September (Autumn), November (Winter). For each month, two different graphs are obtained, one shows the frequency of a particular tilt angle throughout the month, while the other shows the variation of tilt angle vs. day number.

\section{March (Spring)}
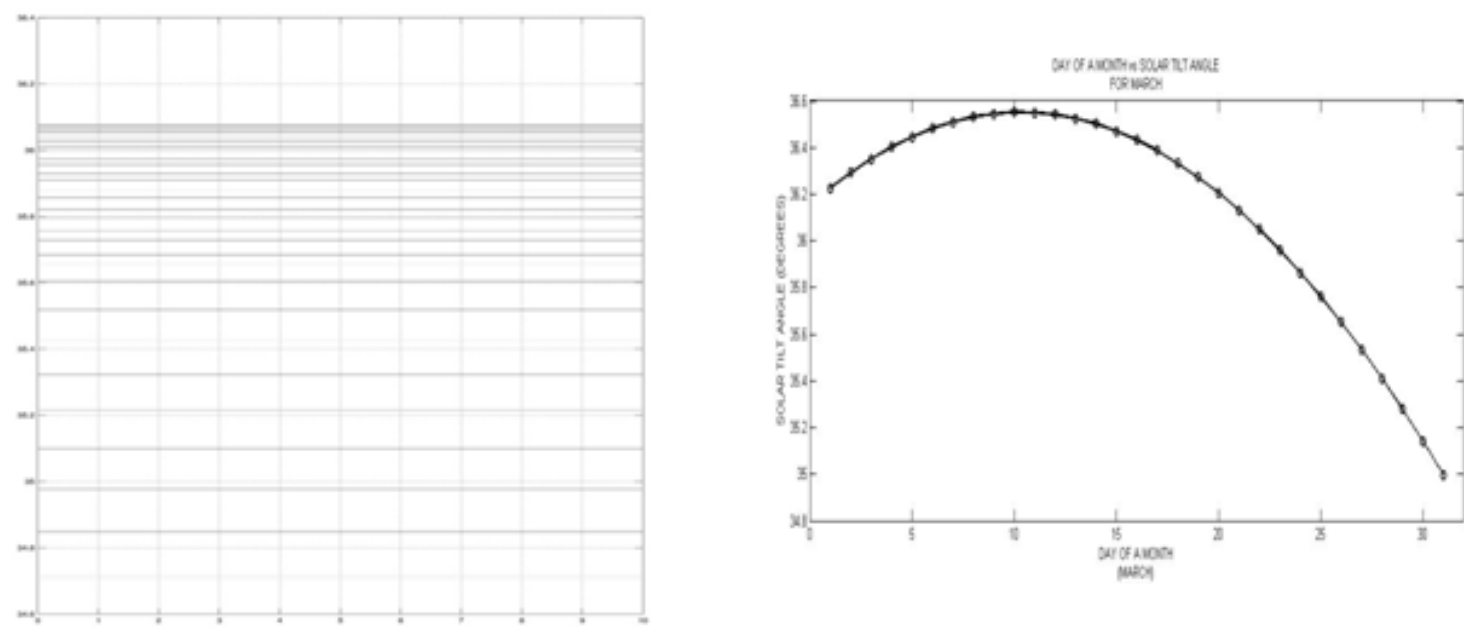

Fig 5 and 6: Frequency and distribution per day of optimum solar tilt angle in the month of March. 


\section{June (Summer)}
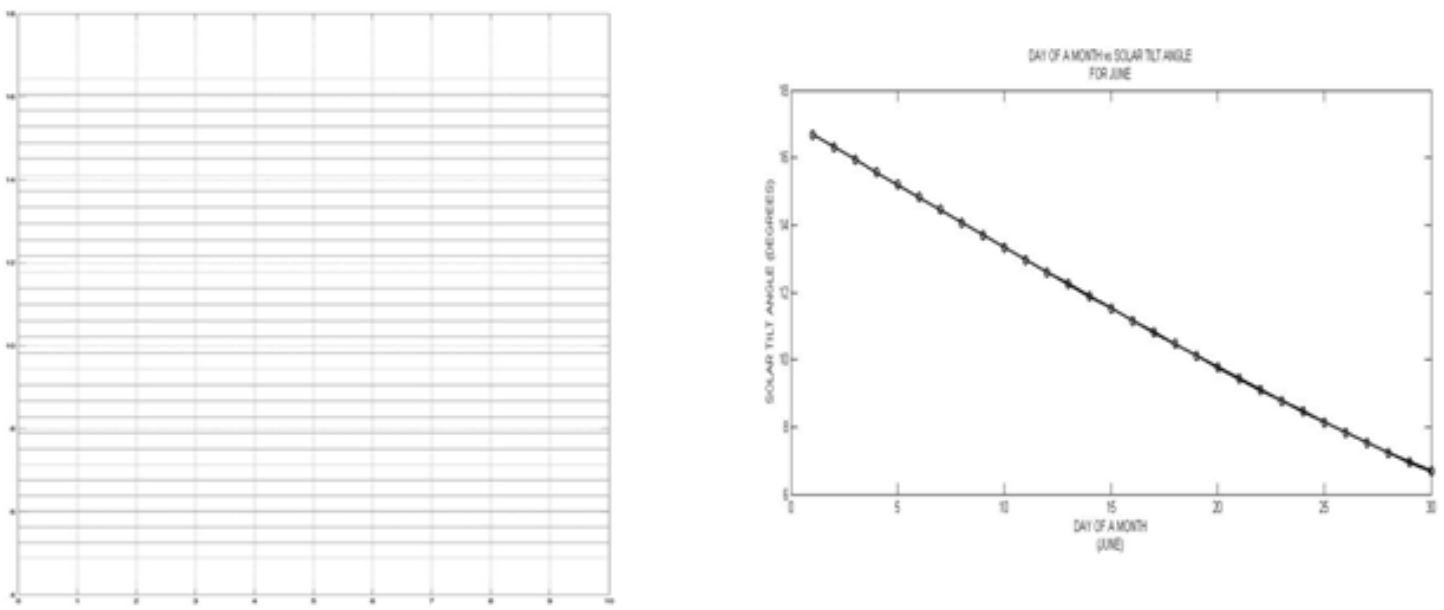

Fig 7 and 8: Frequency and distribution per day of optimum solar tilt angle in the month of June.

\section{September (Autumn)}
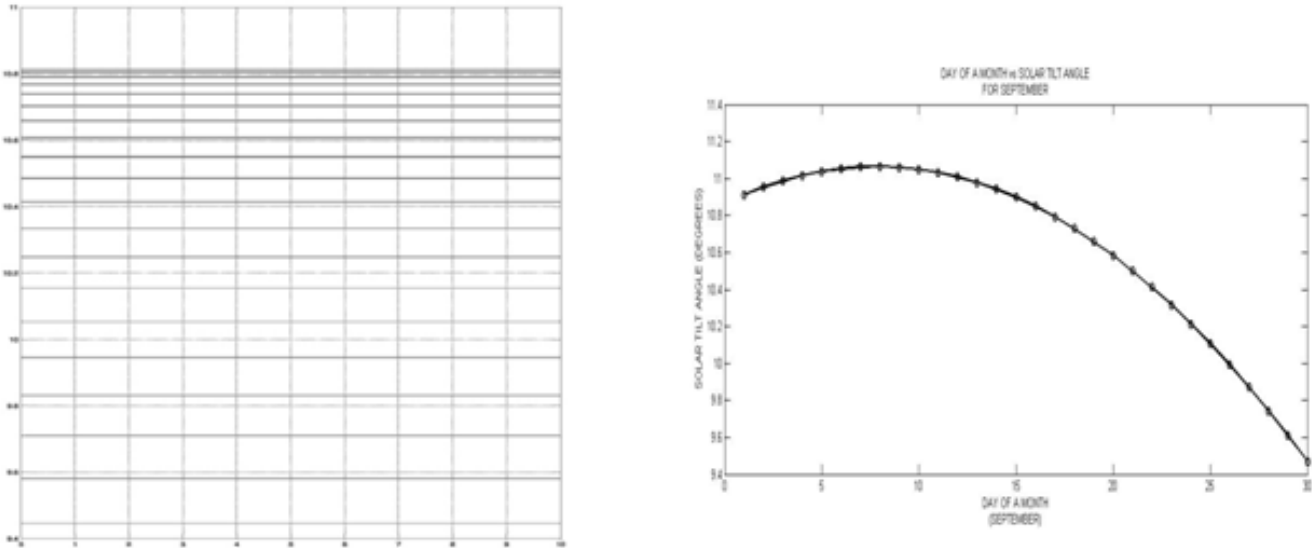

Fig 9 and 10: Frequency and distribution per day of optimum solar tilt angle in the month of September.

\section{November (Winter)}
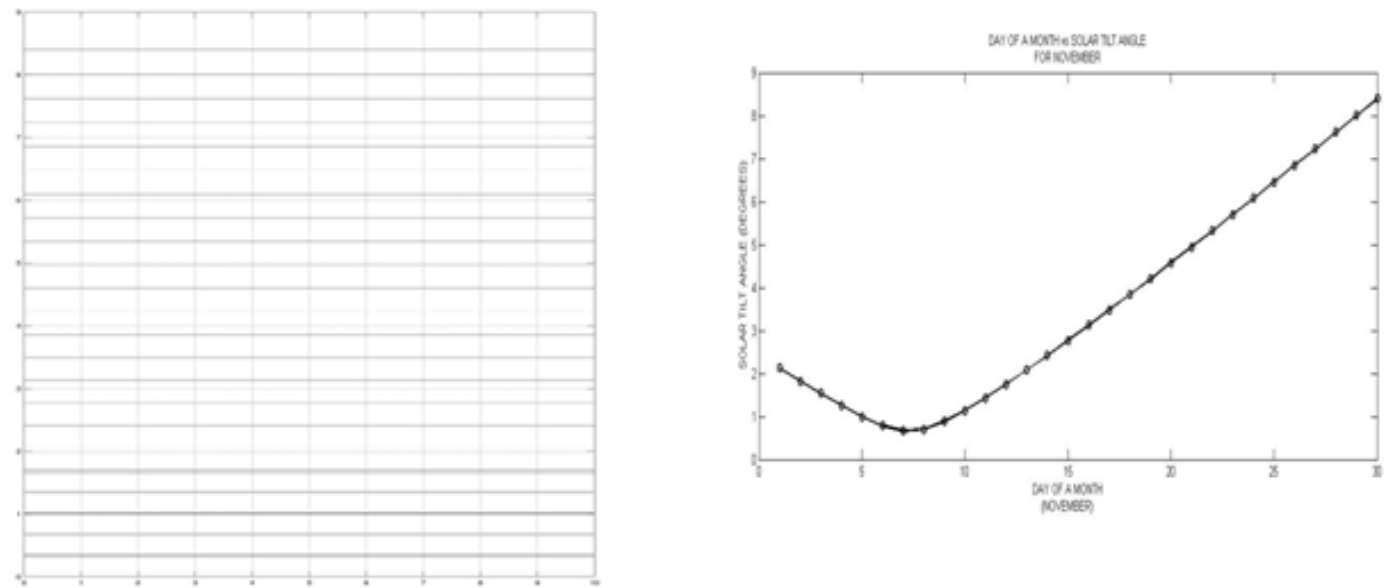

Fig 11 and 12: Frequency and distribution per day of optimum solar tilt angle in the month of November. 


\section{Conclusion}

From the data and calculation it can be inferred that the weighted average method of calculating optimum tilt angle gives a more accurate and significant result when compared to simple averaging. For VIT University, while simple average method gives $17.7093^{\circ}$, the weighted average method gives $19.5640^{\circ}$ which gives a significant percentage deviation of $10.47 \%$. This deviation, won't make much difference in the output of small PV systems, but for PV Systems in the MW range, this mere deviation can help increase the output of the plant. We also notice that this research output gives more weightage to months like march, which has a high solar irradiation. This makes sure that maximum efficiency is obtained in months having good solar input and this increases overall annual efficiency of the panels.

As this output can be obtained without having any information about past data, this research can also help a company to set up plants in remote places having no past data. The Simulink models generalizes the research work for any place with a given longitude and latitude.

This research has a lot of scope for expansion. We have assumed that the maximum radiation is received at 12:00 PM (Solar Time). We can expand this work by not assuming this and taking weights of each hour in a day. Also, we have not taken into consideration the clearness factor which takes into account the irradiation lost at a particular location due to absorption. Apart from this, azimuth angle calculations can be done and tilt of the panel with respect to south direction (for panel in northern hemisphere) can be found out with good accuracy. The MATLAB Simulink model can be developed as the backend of an application which will be easy to use for the people.

\section{Acknowledgements}

We are thankful to the institute and the staffs in encouraging us for this research work. Also, the resources and the help provided by the administration corroborated the work done.

\section{References}

[1]. T. Pavlović, Z. Pavlović, L. Pantić, Lj. Kostić, "DETERMINING OPTIMUM TILT ANGLES AND ORIENTATIONS OF PHOTOVOLTAIC PANELS IN NIŠ, SERBIA", Contemporary Materials I-2 (2010)

[2]. PI Cooper, "The absorption of radiation in solar stills", Solar Energy, Volume 12, 1969

[3]. Formula of Angle of Declination for elliptical orbits: ELEG620: Solar Electric Systems University of Delaware, ECE Spring 2008C. Honsberg.

[4]. M. Narendra Kumar, Kuldip Singh, K. S. R. Anjaneyulu, "Solar Power Analysis Based on Tracking Simulation", International Electrical Engineering Journal (IEEJ), Vol. 5 (2014)

[5]. Reda, I., Andreas, A. (2004). "Solar Position Algorithm for Solar Radiation Applications". Solar Energy (Elsevier) 76 (5): $577-589$. Bibcode:2004SoEn...76..577R. doi:10.1016/j.solener.2003.12.003. ISSN 0038-092X

[6]. M. Benghanem, "Optimization of tilt angle for solar panel: Case study for Madinah, Saudi Arabia", ELSEVIER, Applied Energy 88 (2011) 1427-1433

[7]. Abhishek Agarwal, Vineet Kumar Vashishtha, S.N. Mishra, "Solar Tilt Measurement of Array for Building Application and Error Analysis", INTERNATIONAL JOURNAL of RENEWABLE ENERGY RESEARCH, Vol.2, No.4, 2012

[8]. S. A. Keshavarz, P. Talebizadeh, S. Adalatia, M. A. Mehrabian, M. Abdolzadeh, "Optimal Slope-Angles to Determine Maximum Solar Energy Gain for Solar Collectors Used in Iran", INTERNATIONAL JOURNAL of RENEWABLE ENERGY RESEARCH, Vol.2, No.4, 2012

[9]. Tian Pau Chang, "Study on the Optimal Tilt Angle of Solar Collector According to Different Radiation Types", International Journal of Applied Science and Engineering 2008. 6, 2: 151-161

[10]. Danny H.W. Li and Tony N. T. Lam, "Determining the Optimum Tilt Angle and Orientation for Solar Energy Collection Based on Measured Solar Radiance Data", International Journal of Photoenergy, Volume 2007, Article ID 85402

[11]. Gang Yang, Student Member, IEEE \& Yongxian Du, "The Computer Aided Design Method for Determining the Monthlyn Optimum Tilt Angle of PV Arrays", ICSET 2008

[12]. Ruifeng Yan, Tapan Kumar Saha, Paul Meredith, Shane Goodwin, "Analysis of yearlong performance of differently tilted photovoltaic systems in Brisbane, Australia", ELSEVIER, Energy Conversion and Management 74 (2013) 102-108

[13]. Sukhatme, S. P. (2008). Solar Energy: Principles of Thermal Collection and Storage (3 ed.). Tata McGraw-Hill Education. p. 84. ISBN 0070260648

[14]. Seinfeld, John H.; Pandis, Spyros N. (2006). Atmospheric Chemistry and Physics, from Air Pollution to Climate Change (2 ed.). Wiley. p. 130. ISBN 978-0-471-72018-8

[15]. Duffie, John A.; Beckman, William A. (2013). Solar Engineering of Thermal Processes (4 ed.). Wiley. pp. 13, 15, 20. ISBN 978-0470-87366-3.

[16]. Schowengerdt, R. A. (2007). "Optical radiation models". Remote Sensing. pp. 45-88. doi:10.1016/B978-012369407-2/50005-X. ISBN 9780123694072

[17]. Jacobson, Mark Z. (2005). Fundamentals of Atmospheric Modeling (2 ed.). Cambridge University Press. p. 317. ISBN 0521548659

[18]. Hartmann, Dennis L. (1994). Global Physical Climatology. Academic Press. p. 30. ISBN 0080571638 